\section{Impreglon mit neuem Geschäftsfeld}

it Wirkung zum 1. Dezember 2012 hat Impreglon den Rohr-Beschichtungsbereich der Julius Mieden $\mathrm{GmbH}$ in Bottrop übernommen. Zuvor hatte die Mieden $\mathrm{GmbH}$ den Bereich Gebäudeschutzbeschichtungen bereits an die Bilfinger \& Berger AG verkauft. Mit der Beschichtung von Groß- rohren schließt Impreglon eine Angebotslücke und etabliert einen weiteren Standort im Ruhrgebiet. Über den Kaufpreis haben die Parteien Stillschweigen vereinbart. Mit zur Zeit 27 Standorten in 13 Ländern auf vier Kontinenten ist Impreglon einer der weltweit führenden Oberflächenveredler.

\title{
Dörken MKS präsentiert sich als neues Mitglied im ACS Südwestfalen
}

Enden

nde November 2012 versammel-

die Dörken MKS-Systeme ihre europäischen Lizenznehmer zum jährlichen Treffen und Erfahrungsaustausch. Das Unternehmen präsentierte sich unter anderem als neuer Gesellschafter des ACS - Automotive Center Südwestfalen, wo es zum Thema Gewichtsreduzierung im Automobilbau einen deutlichen Beitrag über die Oberfläche leisten möchte. Das ACS ist ein Gemeinschaftsunternehmen der Automobilzulieferindustrie, der Hochschulen und Kommunen in der Region. Es versteht sich als Plattform für Entwicklungsarbeiten und Wissenstransfer zwischen Automobilherstellern, Zulieferern und Hochschulinstituten mit dem Ziel, die Gewichtsreduzierung im Automobilbau voranzutreiben. Vom Engagement im ACS verspricht sich Dörken MKS-Systeme einen deutlichen Erkenntnisund Kompetenzgewinn beim Thema Leichtbau. Die neuen Kontakte und Erkenntnisse sieht das Unternehmen als entscheidenden Vorsprung, um seine Position als Innovationsführer im Bereich der Mikroschicht-Korrosionsschutz-Systeme weiter auszubauen. Auf der Agenda des Beschichtermeetings standen darüber hinaus das Thema "schwarze Oberflächen" sowie ein neuer Topcoat (Delta-Protekt VH 301.1 GZ) als Weiterentwicklung der silikatischen Versiegelung mit integriertem Schmiermittel. Eine rege Diskussion entstand im Anschluss zwischen dem Unternehmen, seinen Lizenznehmern und einem namhaften Vertreter von VW über die Schwierigkeiten der Umstellung. VW ist als Mitinitiator der Weiterentwicklung des ursprünglichen Topcoats (DeltaProtekt VH 301 GZ) eng in den Vorgang eingebunden. Weitere Themen waren optimierte Vorbehandlungsmetho-den für Zinklamellensysteme und neue Wachstumsmärkte und Tiers, die Jörn Selent in seiner neuen Funktion im Bereich „Global Sales Tiers" vorstellte.

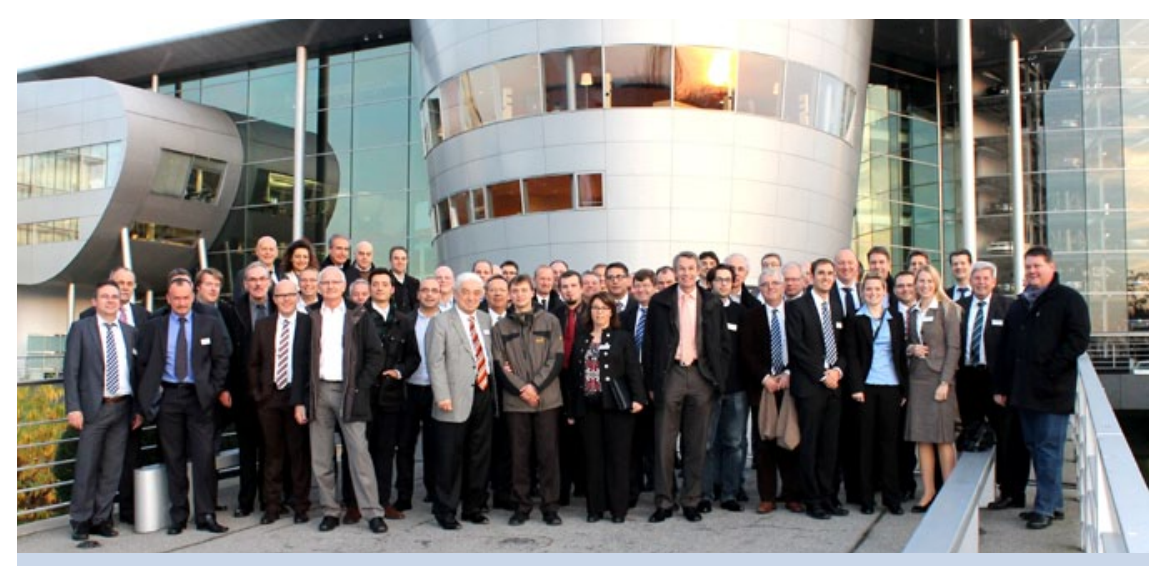

Die europäischen Lizenznehmer der Dörken MKS-Systeme beim alljährlichen

Beschichtermeeting vor der Gläsernen Manufaktur des VW Phaeton in Dresden
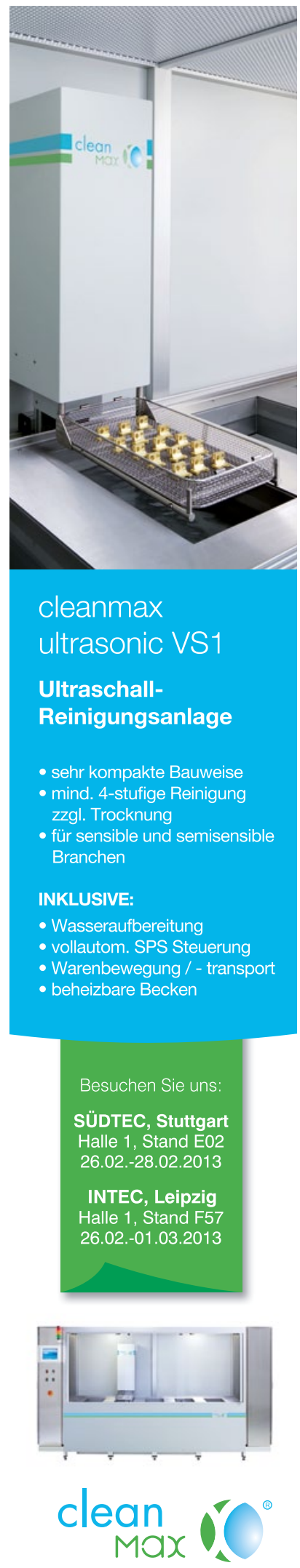

Cleanmax $\mathrm{GmbH}$ Auer Strasse 7, 09366 Stollberg Tel.: +4937296 92723-600

www.clean-max.de 